\title{
Influence of family members on utilization of maternal health care services among teen and adult pregnant women in Kathmandu, Nepal: a cross sectional study
}

\author{
Priti Upadhyay ${ }^{1 *}$, Tippawan Liabsuetrakul ${ }^{1}$, Amir Babu Shrestha ${ }^{2}$ and Neelam Pradhan ${ }^{3}$
}

\begin{abstract}
Background: In some developing countries a woman's decision to utilize maternal health care services is not made by the woman herself but by other family members. The perception of family members regarding who is the most influential person for making the decision to utilize these services is inconclusive. Hence, this study aimed to determine the perceived influential person on utilization of antenatal care (ANC) and delivery care services among teen, young adult and adult pregnant women from the perspective of the woman themselves, their husband and their mother-in-law, identify the factors associated with the woman being the most influential person, and assess the level of agreement between the woman's and her husband's response to the woman being the most influential person.
\end{abstract}

Methods: A cross-sectional study was conducted at Paropakar Maternity and Women's Hospital and Tribhuvan University Teaching Hospital. Purposive sampling technique was used to select 315 women of which 105 were from each age group and their accompanied husbands $(n=315)$ and mothers-in-law $(n=315)$. The proportion of perceived influential person and mean priority score of the perceived influence with its $95 \%$ confidence interval was calculated. The factors associated with the woman perceived as the most influential person were analyzed by multivariate logistic regression model. The agreement was analyzed using kappa statistic.

Results: Among teens and young adults and their husband and mother-in-law, the woman's husband was perceived as the most influential person. Among adults, the most influential person for ANC was the woman herself but for delivery care was the woman's husband. A woman of adult age, having a non-indigenous ethnicity or who was not referred was more likely to perceive herself as the most influential person in the decision to utilize delivery care. A fair to poor level of agreement was found on the perception of the most influential person for ANC and delivery care utilization.

Conclusions: Both women and their husbands influenced the decision to utilize ANC and delivery care but husbands were more influential, especially in teens and young adults. Thus, husband's involvement is crucial as a strategy to improve maternal health care utilization in Nepal.

Keywords: Influence, Family members, Husband, Mother-in-law, Utilization, Maternal health care services, Antenatal care, Delivery, Teens, Adults

\footnotetext{
* Correspondence: u.priti@gmail.com

${ }^{1}$ Epidemiology Unit, Faculty of Medicine, Prince of Songkla University, Hat

Yai, Songkhla, Thailand, 90110

Full list of author information is available at the end of the article
}

\section{Biomed Central}

(c) 2014 Upadhyay et al.; licensee BioMed Central. This is an Open Access article distributed under the terms of the Creative Commons Attribution License (http://creativecommons.org/licenses/by/4.0), which permits unrestricted use, distribution, and reproduction in any medium, provided the original work is properly credited. The Creative Commons Public Domain Dedication waiver (http://creativecommons.org/publicdomain/zero/1.0/) applies to the data made available in this article, unless otherwise stated. 


\section{Background}

In 2010, 99\% of all global maternal deaths occurred in developing countries [1]. Compared to women aged over 20 years, the risks of maternal death among teens aged 15-19 years is twice as high and is almost five times higher among those under 15 years [2]. Likewise, the risk of stillbirth and neonatal death in the first week of life is higher among newborns of mothers who are aged younger than 20 years [3]. Maternal and perinatal deaths and related complications can be averted by timely and adequate utilization of antenatal care (ANC) and delivery care services $[4,5]$.

Low utilization of maternal health care services and increased risks for obstetric complications among pregnant teens has been reported from both developed and developing countries [6-10]. As a result, teens are a vulnerable group and need more attention for their care seeking behaviors when they become pregnant. In developing countries in Africa and Asia, particularly Nepal, low utilization of maternal health care services was observed, among teens and adults [11-13].

The proportion of births attended by skilled health personnel and ANC coverage (the percentage of women aged 15-49 with a live birth that received ANC by any provider four or more times during their pregnancy), two of the WHO indicators for improving maternal and child health, have improved globally [14]. Although the government of Nepal implemented the safe delivery incentive program in 2005 and a national free delivery policy in 2009, Nepal has not achieved the Millenium Development Goal 5 (MDG5) targets for these indicators yet. The latest national data in 2013 showed that only $50 \%$ of women had achieved both MDG 5 targets while the target to meet by 2015 is $80 \%$ for four ANC visits and $60 \%$ for delivery attended by skilled birth attendant [15-17]. A higher utilization of facility-based services was evident in semi-urban regions of Kathmandu district with $70 \%$ of deliveries attended by a skilled birth attendant. Lower utilization in remote regions of Nepal might be explained by the cultural tradition of giving birth in the community and women's lack of power to demand the services if their partners show discouragement $[18,19]$.

It is evident that the factors associated with utilization of obstetric care in facilities in developing countries such as Nepal are multifactorial and include demographic, economic, socio-cultural or religious characteristics [20-23]. Apart from the women's individual and household factors, it was reported in Africa and South Asia that the decision to utilize maternal health care services was not made by the woman herself but by her husband or other family members [3,24,25]. Six previous studies conducted in Nepal, Bangladesh, Burkina Faso, Thailand, Kenya and Pakistan determined the influential persons for making the decision to utilize maternal care; however, the study samples, methodologies and data analyses were different to ours [24-29]. The study from Nepal was qualitative and interviewed women, their husbands and their mothers-inlaw [24]. Four studies interviewed only women among which two were qualitative and two were quantitative [25,27-29]. The remaining one was also a qualitative study which interviewed both women and their husbands [26]. The findings of qualitative studies were limited by the small sample size. In addition, the methodologies applied to identify the most influential person were not clearly explained in the previous studies. Additionally, previous studies on household decision making have revealed that the women's autonomy was positively associated with age suggesting that the influential persons might vary depending on age [30,31].

Increasing the effort to improve ANC coverage and the proportion of births attended by skilled birth attendants is a challenge in the countries of Africa and South Asia. The efforts may be useless if the relevant persons who participate in the decision making process are not taken into account. Therefore, there is a need to identify the influential person on making decision to utilize these services. Knowing the influential persons among the family members of the pregnant women and in different age groups is essential to prepare the strategies and targets of promotion of maternal health care services. This study thus aimed to determine the perceived influential person on a woman's decision to utilize antenatal and delivery care services among teen, young adult and adult pregnant women from the perspective of themselves, their husband and their mother-in-law, identify the factors associated with the woman being the most influential person in the decision to utilize care, and assess the level of agreement between the woman's and husband's response to the woman being the most influential person.

\section{Methods}

\section{Study design and setting}

A cross-sectional study was conducted at Paropakar Maternity and Women's Hospital (PMWH) and Tribhuvan University Teaching Hospital (TUTH) which provides maternity services in Kathmandu district of Nepal, from June to October 2013. The PMWH is the main public maternity hospital of Kathmandu having more than 18,000 deliveries per year and the TUTH is a university hospital having more than 5,000 deliveries per year in 2013.

\section{Study sample}

Women aged 34 or less, who delivered at PMWH or TUTH and were accompanied by both their husband and mother-in-law at any time of their hospitalization were purposively included. The sample also consisted of the accompanying husband and mother-in-law. Eligible 
women, their husbands and mothers-in-law were mostly identified at the postpartum ward by asking the women whether her husband and mother-in-law had accompanied her or would visit her at this admission. Some women were also identified when the woman's husband or mother-in-law were waiting outside the labor room. All women, their husbands and mothers-in-law were informed that they had the right to agree or refuse to participate in the study and each of them was approached separately and independently.

The sample size was calculated on the basis of estimating the proportion of women whose family members influenced her to utilize ANC and delivery care services. Considering this estimated proportion to be $50 \%$, to be $95 \%$ confident of estimating this proportion with a precision of $10 \%$, at least 96 women were needed. We assumed that the influence of family members on women of different age groups may not be same, thus the sample size was separated into three age groups: teens (less than 20 years), young adults (20-24 years) and adults (25-34 years). As a result, at least 288 women and their husbands and mothers-in-law were required. Sample sizes were determined for each hospital based on the probability proportional to the number of deliveries in each hospital. The proportion of past deliveries was approximately $70 \%$ and $30 \%$ in PMWH and TUTH respectively, which lead to the sample size of 205 for PMWH and 110 for TUTH.

\section{Data collection}

After individually signing the consent forms, all respondents were interviewed separately in a private place within the hospital using a structured questionnaire. The interviews of the women were done exclusively in the postpartum period before the women were discharged from the hospital. The interviews of the husbands and mothers-inlaw were performed in either the postpartum or delivery period as appropriate. All interviews were conducted by the first author. All women, husbands and mothers-in-law were interviewed using the same questionnaire.

\section{Variables}

The main outcome variable was the person who had the most influence on the woman's decision to utilize ANC and delivery care at the hospital. The question asked to all three persons was "When you/your spouse/your daughterin-law needed ANC /delivery care for this pregnancy, who were the influential persons on your/your wife's/ your daughter-in-law's decision to utilize this care?" with four possible persons, namely the woman, husband, mother-in-law and others. If they responded multiple answers then they were asked to rank the priority of each influential person from the most to the least with no ties allowed. The person who was ranked the highest for each respondent was defined as the most influential person as either the woman or others.

Independent variables included socio-demographic characteristics of the women, husband and mother-inlaw and obstetric characteristic of the women.

\section{Statistical analysis}

Double data entry and validation was performed using EpiData. The analysis was done in $\mathrm{R}$ (The $\mathrm{R}$ Foundation for Statistical Computing, Vienna, Austria). The characteristics of women, their husbands and their mothers-inlaw were analyzed using Chi square or Fisher's exact test as appropriate for categorical variables and Wilcoxon's Rank Sum test for continuous variables.

The proportion of each influential person by the three types of respondents and three age groups for both ANC and delivery care was determined and the mean priority score was calculated with $95 \%$ confidence interval. The priority ranks were summed and then averaged for each person. Higher mean scores indicated a greater influence of that person on the woman's decision to utilize ANC and delivery care.

The factors associated with women being perceived as the most influential person on the decision to utilize ANC and delivery care by women's perspective were assessed by uni-variate and multiple logistic regression models. A p-value less than 0.05 was considered as statistically significant. Agreement between women's and their husbands' perspectives on whether the woman was the most influential person on the utilization of both ANC and delivery care was analyzed using both unadjusted and prevalence adjusted kappa statistic among the three age groups [32].

\section{Ethical considerations}

The study protocol was approved by the Ethical Committee of the Faculty of Medicine, Prince of Songkla University, Songkhla, Thailand. The permission for conducting data collection in the participating hospitals was obtained. All respondents were provided with information about the study, and written informed consent was received before the interview. Involvement in the study did not place the respondents at any risk. Data were collected anonymously to ensure confidentiality.

\section{Results}

A total of 315 women with their husbands and mothers-in-law were interviewed in the study period of which 105 in each age group were included. The sociodemographic and obstetric characteristics of women are presented in Tables 1 and 2 respectively. There were a significantly higher proportion of indigenous teens in the study sample. A significantly higher proportion of teens also resided outside of Kathmandu 
Table 1 Comparison of women's socio-demographic characteristics of by age group

\begin{tabular}{|c|c|c|c|c|c|}
\hline Characteristics & $\begin{array}{c}\text { Teens }(\mathrm{N}=105) \\
\mathrm{n}(\%)\end{array}$ & $\begin{array}{l}\text { Young adults } \\
(N=105) n(\%)\end{array}$ & $\begin{array}{c}\text { Adults }(\mathrm{N}=105) \\
\mathrm{n}(\%)\end{array}$ & $\begin{array}{c}\text { Total }(\mathrm{N}=315) \\
\mathrm{n}(\%)\end{array}$ & P-value \\
\hline Ethnicity & & & & & 0.02 \\
\hline Indigenous & $72(68.6)$ & $55(52.4)$ & $56(53.3)$ & $183(58.1)$ & \\
\hline Non-indigenous & $33(31.4)$ & $50(47.6)$ & $49(46.7)$ & $132(41.9)$ & \\
\hline Religion & & & & & 0.08 \\
\hline Hindu & $80(76.2)$ & $90(85.7)$ & $91(86.7)$ & $261(82.9)$ & \\
\hline Buddhist or others & $25(23.8)$ & $15(14.3)$ & $14(13.3)$ & $54(17.1)$ & \\
\hline Residency & & & & & 0.001 \\
\hline Within Kathmandu & $82(78.1)$ & $89(84.8)$ & $100(95.2)$ & $271(86)$ & \\
\hline Outside Kathmandu & $23(21.9)$ & $16(15.2)$ & $5(4.8)$ & $44(14.0)$ & \\
\hline Occupation & & & & & $<0.001$ \\
\hline Housewife & $78(74.3)$ & $56(53.3)$ & $51(48.6)$ & $185(58.7)$ & \\
\hline Employed & $8(7.6)$ & $37(35.2)$ & $44(41.9)$ & $89(28.3)$ & \\
\hline Farmer or laborer & $19(18.1)$ & $12(11.4)$ & $10(9.5)$ & $41(13.0)$ & \\
\hline Education & & & & & $<0.001$ \\
\hline Illiterate or can only read and write & $7(6.7)$ & $4(3.8)$ & $13(12.4)$ & $24(7.6)$ & \\
\hline Primary or secondary & $90(85.7)$ & $75(71.4)$ & $65(61.9)$ & $230(73.0)$ & \\
\hline University degree or higher & $8(7.6)$ & $26(24.8)$ & $27(25.7)$ & $61(19.4)$ & \\
\hline Marriage arrangement & & & & & $<0.001$ \\
\hline By self or partner & $73(69.5)$ & $57(54.3)$ & $42(40)$ & $172(54.6)$ & \\
\hline By family & $32(30.5)$ & $48(45.7)$ & $63(60)$ & $143(45.4)$ & \\
\hline Age at marriage & & & & & $<0.001$ \\
\hline Less than 20 years & $105(100)$ & $50(47.6)$ & $18(17.1)$ & $173(54.9)$ & \\
\hline More than or equal to 20 years & - & $55(52.4)$ & $87(82.9)$ & $142(45.1)$ & \\
\hline
\end{tabular}

valley and had no formal occupation. They had a lower proportion who had attained a higher educational degree and had their marriage arranged by their family. A higher proportion of teens attended their first ANC after four months gestation, had less than four ANC visits and had a low perceived willingness to utilize ANC.

Table 3 compares the characteristics of the women's husbands and mothers-in-law. The median ages of husbands and mothers-in-law increased with increasing age group. Husbands of teens had a lower proportion of higher educational attainment and employment. The majority $(>80 \%)$ of mothers-in-law had not attended formal education regardless of the age of the women. The proportion of housewives among the mothers-in-law of adult women was twice as high as that of young adults and teens. Slightly more than half of mothers-in-law currently lived with their daughter-in-law.

Figure 1 shows the proportion of influential persons perceived by the three types of respondents on the decision to utilize facility-based ANC and delivery care stratified by the women's age groups. Approximately $90 \%$ or more of women and their husbands and mothers-in-law in all three age groups rated that the woman and her husband were influential persons in the decision to utilize both services. Mothers-in-law were rated to be the lowest influential person by three types of respondents for both services, especially in the adult group and its proportion of influence was lower in ANC than in delivery care.

The mean priority scores of women, husbands and mothers-in-law as the influential person in the decision to utilize ANC and delivery care rated by three types of respondents among three age groups are shown in Figures 2 and 3. For ANC (Figure 2), the husband was ranked to be the highest among teens and young adults. Among adults, women were ranked the highest followed closely by husbands. Both women and husbands perceived that the woman was more influential than the mother-in-law across all age groups but the mother-inlaw perceived her influence on her daughter-in-law's utilization of ANC among teens and young adults. For delivery care (Figure 3), the husband was also ranked as the most influential person in all age groups. The influence of women in their decision to utilize delivery care was ranked the lowest by all three respondents among the teen age group. 
Table 2 Comparison of women's obstetric characteristics of by age group

\begin{tabular}{|c|c|c|c|c|c|}
\hline Characteristics & $\begin{array}{c}\text { Teens }(\mathrm{N}=105) \\
\mathrm{n}(\%)\end{array}$ & $\begin{array}{l}\text { Young adults } \\
(\mathrm{N}=105) \mathrm{n}(\%)\end{array}$ & $\begin{array}{c}\text { Adults }(\mathrm{N}=105) \\
\mathrm{n}(\%)\end{array}$ & $\begin{array}{c}\text { Total }(\mathrm{N}=315) \\
\mathrm{n}(\%)\end{array}$ & P-value \\
\hline Parity & & & & & $<0.001$ \\
\hline Primiparous & $98(93.3)$ & $86(81.9)$ & $45(42.9)$ & $229(72.7)$ & \\
\hline Multiparous & $7(6.7)$ & $19(18.1)$ & $60(57.1)$ & $86(27.3)$ & \\
\hline Gravida & & & & & $<0.001$ \\
\hline Primigravida & $88(83.8)$ & $75(71.4)$ & $37(35.2)$ & $200(63.5)$ & \\
\hline Multigravida & $17(16.2)$ & $30(28.6)$ & $68(64.8)$ & $115(36.5)$ & \\
\hline Intention of current pregnancy & & & & & 0.067 \\
\hline Not sure/No & $45(42.9)$ & $29(27.6)$ & $36(34.3)$ & $110(34.9)$ & \\
\hline Yes & $60(57.1)$ & $76(72.4)$ & $69(65.7)$ & $205(65.1)$ & \\
\hline Type of hospital for ANC & & & & & 0.002 \\
\hline Only Public & $93(88.6)$ & $83(79.0)$ & $77(73.3)$ & $253(80.3)$ & \\
\hline Only Private & $7(6.7)$ & $7(6.7)$ & $3(2.9)$ & $17(5.4)$ & \\
\hline Both public and private & $5(4.8)$ & $15(14.3)$ & $25(23.8)$ & $45(14.3)$ & \\
\hline Gestational age at first ANC & & & & & 0.02 \\
\hline Within four months & $59(56.2)$ & $75(71.4)$ & $75(71.4)$ & $209(66.3)$ & \\
\hline After four months & $46(43.8)$ & $30(21.6)$ & $30(21.6)$ & $106(33.7)$ & \\
\hline Number of ANC visits & & & & & 0.003 \\
\hline Less than four times & $16(15.2)$ & $2(1.9)$ & $10(9.5)$ & $28(8.9)$ & \\
\hline More than four times & $89(84.8)$ & $103(98.1)$ & $95(90.5)$ & $287(91.1)$ & \\
\hline Referral status & & & & & 0.008 \\
\hline Not referred from another hospital & $88(83.8)$ & $89(84.8)$ & $101(96.2)$ & $278(88.3)$ & \\
\hline Referred from another hospital & $17(16.2)$ & $16(15.2)$ & $4(3.8)$ & $37(11.7)$ & \\
\hline Perceived willingness to utilize ANC & & & & & 0.03 \\
\hline Low & $26(24.8)$ & $12(11.4)$ & $17(16.2)$ & $55(17.5)$ & \\
\hline High & $79(75.2)$ & $93(88.6)$ & $88(83.8)$ & $260(82.5)$ & \\
\hline Perceived willingness to utilize delivery care & & & & & 0.9 \\
\hline Low & $12(11.4)$ & $10(9.5)$ & $11(10.5)$ & $33(10.5)$ & \\
\hline High & 93 (88.6) & $95(90.5)$ & $94(89.5)$ & $282(89.5)$ & \\
\hline
\end{tabular}

Of all women, $44 \%$ and $33 \%$ of them perceived themselves to be the most influential person for making the decision to utilize ANC and delivery care respectively. Table 4 presents the factors associated with the woman being the most influential person in the decision to utilize ANC and delivery care. Women's age group, ethnicity and referral status were significant factors for utilization of ANC while age group and ethnicity were the only significant factors for delivery care utilization. For ANC, young adult females and adult females, compared to teen females, perceived that they were the most influential person to make the decision (Adjusted odds ratio (AOR) 2.12; 95\% Confidence interval (CI) 1.18-3.79 for young adults and AOR 3.14; 95\% CI 1.76-5.63 for adults). For delivery care, adult females were more likely to perceive themselves to be the most influential person (AOR 2.9; 95\% CI 1.56-5.38). Non-indigenous women perceived that they were the most influential person to make the decision for both ANC (AOR 1.77; 95\% CI 1.11-2.83) and delivery care (AOR 1.71; 95\% CI 1.04-2.8). For delivery care, those who were not referred from other hospitals were more likely to perceive themselves to be the most influential person compared to those who were referred from other hospitals (AOR 3.77; 95\% CI 1.27-11.15).

Table 5 presents the agreement between the woman and her husband on the most influential person on the woman's decision to utilize ANC and delivery care. The observed agreement ranged from $55.2 \%$ to $60 \%$ for ANC and $55.2 \%$ to $66.7 \%$ for delivery care utilization. Fair to poor agreement (prevalence-adjusted kappa coefficient 0.1 to 0.3 ) was found for both services of which poor agreement was observed among adults. The proportion of other persons rated as the most influential person by 
Table 3 Characteristics of husbands and mothers-in-law by women's age group

\begin{tabular}{|c|c|c|c|c|c|}
\hline Characteristics & $\begin{array}{c}\text { Teens }(\mathrm{N}=105) \\
\mathrm{n}(\%)\end{array}$ & $\begin{array}{l}\text { Young adults } \\
(\mathrm{N}=105) \mathrm{n}(\%)\end{array}$ & $\begin{array}{c}\text { Adults }(\mathrm{N}=105) \\
\mathrm{n}(\%)\end{array}$ & $\begin{array}{c}\text { Total }(\mathrm{N}=315) \\
\mathrm{n}(\%)\end{array}$ & P-value \\
\hline \multicolumn{6}{|l|}{ Husband's characteristics } \\
\hline \multicolumn{6}{|l|}{ Age } \\
\hline Median (IQR) & $23(21,24)$ & $26(24,29)$ & $30(28,33)$ & $26(23,30)$ & $<0.001^{*}$ \\
\hline Education & & & & & $<0.001^{* *}$ \\
\hline Illiterate or can only read and write & $3(2.9)$ & $1(0.9)$ & $4(3.8)$ & $8(2.5)$ & \\
\hline Primary or secondary & $92(87.6)$ & $77(73.3)$ & $64(60.9)$ & $233(73.9)$ & \\
\hline University degree or higher & $9(8.6)$ & $27(25.7)$ & 37 (35.2) & $74(23.2)$ & \\
\hline Occupation & & & & & $0.02^{* *}$ \\
\hline Unemployed & $5(4.8)$ & $4(3.8)$ & $3(2.9)$ & $12(3.8)$ & \\
\hline Employed & $60(57.1)$ & 79 (75.2) & $79(75.2)$ & $218(69.2)$ & \\
\hline Farmer or others & $40(38.1)$ & $22(21)$ & $23(21.9)$ & $83(26.3)$ & \\
\hline Type of family & & & & & 0.2 \\
\hline Nuclear & $33(31.4)$ & $40(38.1)$ & $45(42.9)$ & $108(34.3)$ & \\
\hline Joint & $72(68.6)$ & $65(61.9)$ & $60(57.1)$ & $197(62.5)$ & \\
\hline Per capita income & & & & & 0.7 \\
\hline$<700$ USD & $72(68.6)$ & $73(69.5)$ & $68(64.8)$ & $213(67.6)$ & \\
\hline$\geq 700$ USD & $33(31.4)$ & $32(30.5)$ & $37(35.2)$ & $102(32.4)$ & \\
\hline \multicolumn{6}{|l|}{ Mother-in-law's characteristics } \\
\hline Age & & & & & $<0.001^{*}$ \\
\hline Median (IQR) & $45(42,50)$ & $50(45,55)$ & $55(50,60)$ & $50(45,55)$ & \\
\hline Education & & & & & 0.2 \\
\hline Illiterate or can only read and write & $88(83.8)$ & $87(82.9)$ & $95(90.5)$ & $270(85.7)$ & \\
\hline Secondary or lower & $17(16.2)$ & $18(17.1)$ & $10(9.5)$ & $45(14.3)$ & 0.2 \\
\hline Occupation & & & & & $<0.001$ \\
\hline Housewife & $25(23.8)$ & $26(24.8)$ & $52(49.5)$ & $103(32.7)$ & \\
\hline Farmer or laborer & $68(64.8)$ & $63(60)$ & $48(45.7)$ & $174(55.2)$ & \\
\hline Employed & $12(11.4)$ & $16(15.2)$ & $5(4.8)$ & $33(10.5)$ & \\
\hline Lives with daughter-in-law & & & & & 0.09 \\
\hline No & $43(41)$ & $39(37.1)$ & $54(51.4)$ & $136(43.2)$ & \\
\hline Yes & $62(59)$ & $66(62.9)$ & $51(48.6)$ & $179(56.8)$ & \\
\hline
\end{tabular}

both husband and women was detected among teens (51.4\%), young adults $(40.0 \%)$ and adults $(22.8 \%)$ for ANC and among teens (60.0\%), young adults $(55.2 \%)$ and adults (31.4\%) for delivery care.

\section{Discussion}

In our study, women, along with their husbands and mothers-in-law, all perceived that the husband was the most influential person in the woman's decision to utilize ANC and delivery care, particularly in teens and young adults. In contrast, adult women, along with their husbands and mothers-in-law perceived the woman to be the most influential person for utilization of ANC services. A woman aged 25-34, having a non-indigenous ethnicity or who was not referred from another hospital was more likely to perceive herself as the most influential person for making the decision to utilize delivery care services. The level of agreement between a woman and her husband on the most influential person was poor to fair.

In our study, a high proportion of the women and their husbands were perceived to be influential person but the husband was found to be more influential based on our ranking technique. The influential person on the decision to utilize maternal health care services differs among countries and might be explained by the differences in cultural, social and health system contexts as well as variations in the measurement technique. The 


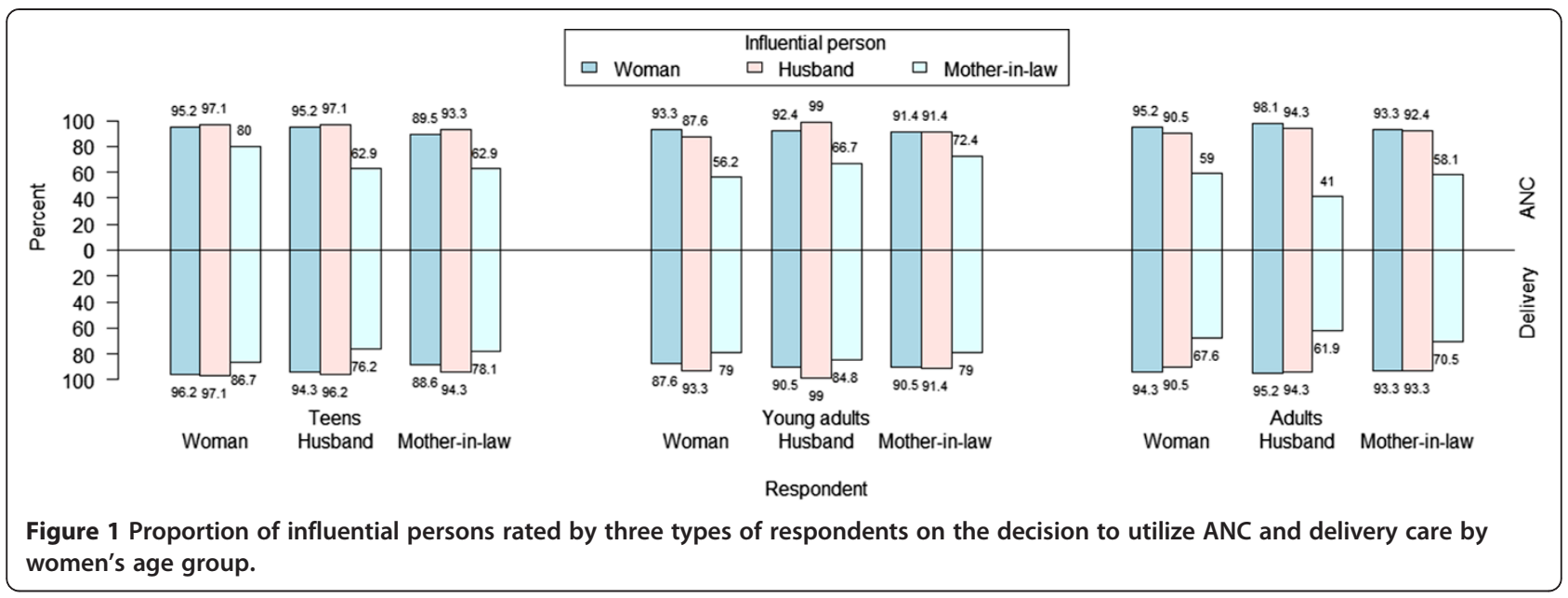

influence of the husband as the main decision maker for a woman's utilization of maternal health services found in this study was also found in previous studies in Bangladesh, Burkina Faso, Tanzania and Nepal [24-26,33]. However, a study in Thailand found that the women themselves influenced their own decision on utilization of delivery care more than other family members [27]. In Nepal and other South Asian and African countries which have patriarchal societies, males are prominent in making the decisions $[24,34]$. This may be related to being a household head and financial authority as approximately $88 \%$ of women in our study said that the hospital expenditure was paid by their husband (data not shown). On the other hand, in Thailand, gender equality [35] and universal health coverage [36] have given women more empowerment.

In addition to the couple, the mother-in-law could be a person who influences the decision to utilize maternal health care services [24,25]. A community-based study in Mali found that the traditional belief by the motherin-law of home delivery influenced the place of delivery [34]. However, the influence of the mother-in-law was not as prominent as the husband's or woman's influence in our study. This might be related to the study setting being an urban area while the previous three studies were conducted in rural areas where the traditional society persists and imparts greater power to the motherin-law in the management of household and health decisions $[25,37,38]$. Nuclear families are free from the influence of mothers-in-law, who do not live in the same household and this is prominent in urban settings. The explanation of more influence of the mother-in-law in delivery care than ANC could not be explained but it may be related to more traditional beliefs in delivery care than in ANC.

The proportion of women perceiving themselves as the most influential person in the decision to utilize delivery care in our study was lower than reported from
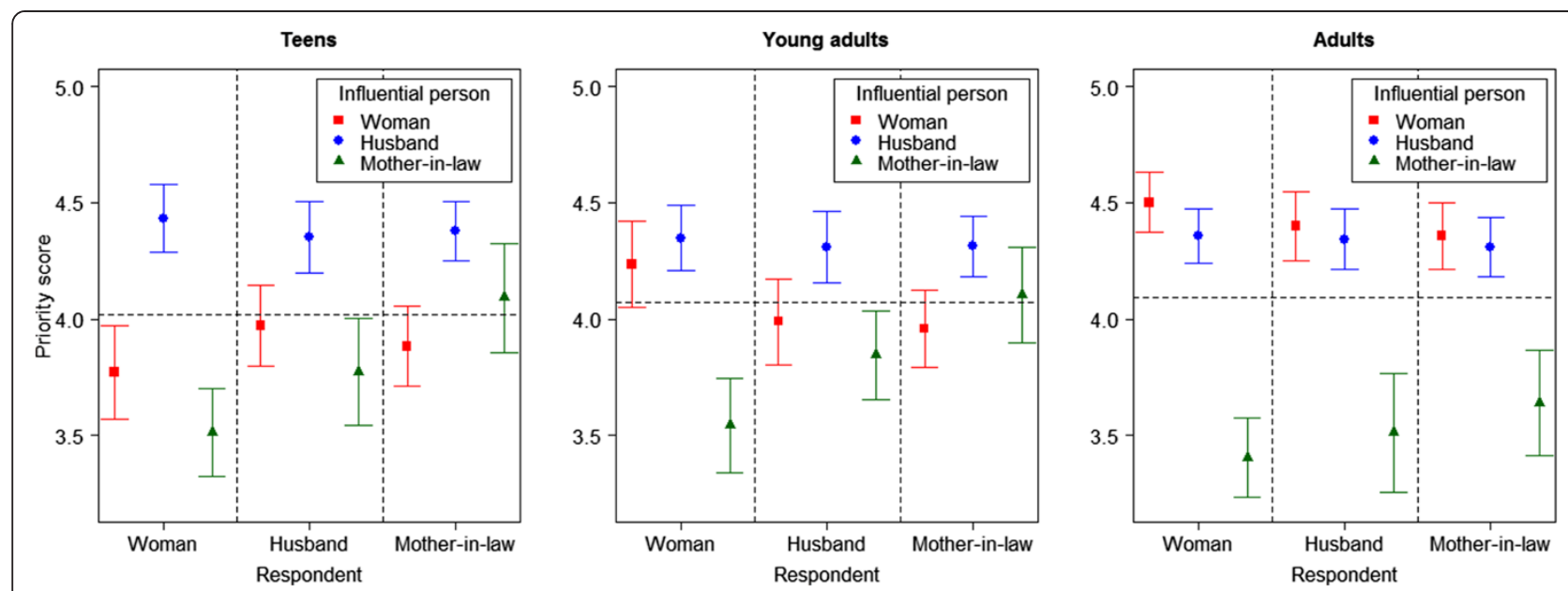

Figure 2 Comparison of mean priority scores for influential persons on decision to utilize ANC services by age groups. 

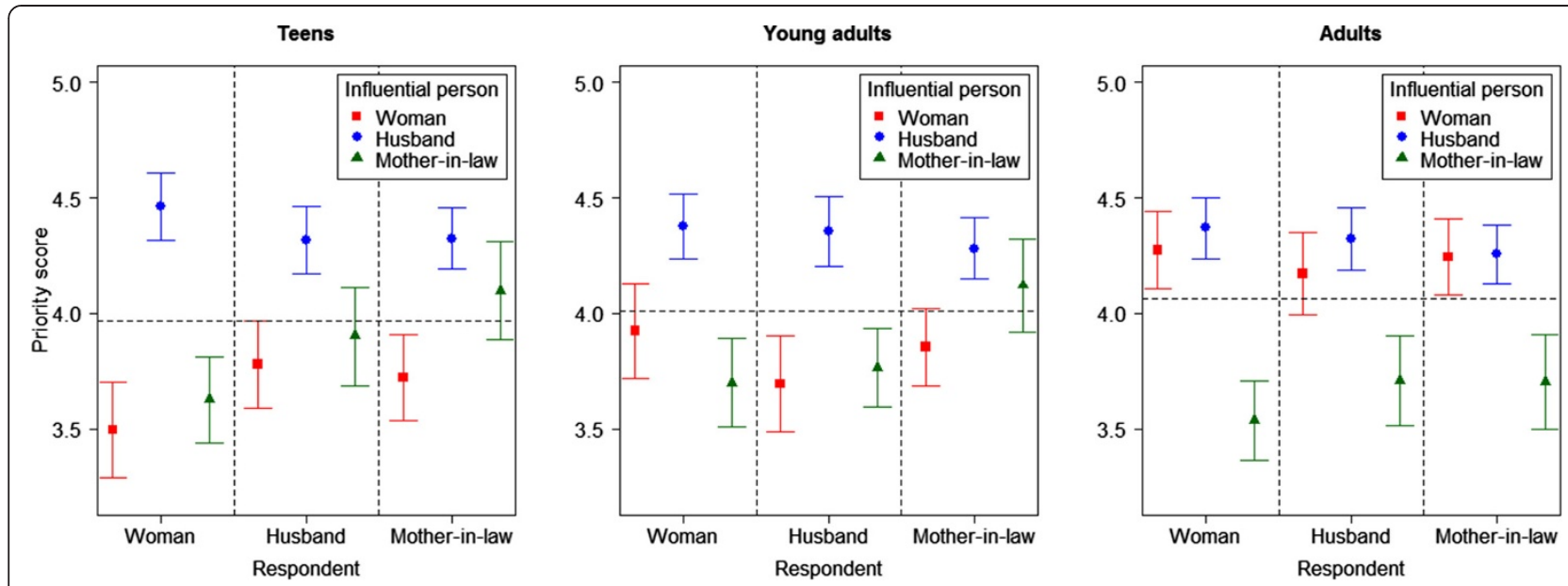

Figure 3 Comparison of mean priority scores for influential persons on decision to utilize delivery care services by age groups.

a study in Kenya but higher than that from a study in Pakistan. However, in both studies the assessment of the decision maker was done differently than in our study $[28,29]$. Adult women were more independent in decision making which was supported by two studies conducted in South Asian countries and age was positively associated with the household decision-making autonomy [30,31]. In a study from Tanzania, teen pregnant women were more likely to receive advice from their mother or a close person rather than from their partner in comparison to adult women [12]. A report from the World Health Organization (WHO) also mentioned that young women including teens had a lack of authority for decision making or resources for using health services [39]. Women with non-indigenous ethnicity belong to an upper social class in Nepal and were found to be more empowered than indigenous women [40]. This might be the possible explanation for non-indigenous women perceiving themselves as the the most influential person on decisionmaking processes. For the referral status result, emergency obstetrics incur higher health expenditures for referral cases where the decision makers were the husband or other family members [33,41].

Poor to fair agreement was found between the women's and their husbands' responses on the most influential person for utilization of maternal health services. This result was similar to results from previous studies on spousal agreement in household decisionmaking, family planning and maternal health behaviours. The agreement on the issues of health decision making and the influential person are subjective and depends on the spousal communication $[42,43]$.

There were a few limitations in our study. First, the purposive sampling technique in our study may have reduced the representativeness of the study sample to the Nepalese population. Second, the samples were independent of type of delivery, area of admission (general ward or special cabin) and referral status, which might have influenced the woman's decision to utilize the services. Third, the study involved facility-based data

Table 4 Final logistic regression model identifying factors associated with women being perceived as the most influential person on decision to utilize ANC delivery care

\begin{tabular}{|c|c|c|c|c|c|c|}
\hline \multirow[t]{3}{*}{ Factors } & \multicolumn{3}{|c|}{ ANC } & \multicolumn{3}{|c|}{ Delivery } \\
\hline & \multicolumn{3}{|c|}{$N=315$} & \multicolumn{3}{|c|}{$N=315$} \\
\hline & AOR $(95 \% \mathrm{Cl})$ & P-value $^{*}$ & P-value ${ }^{* *}$ & AOR $(95 \% \mathrm{Cl})$ & P-value ${ }^{*}$ & P-value ${ }^{* *}$ \\
\hline Age group of women: ref. $=$ Teens & & & $<0.001$ & & & 0.002 \\
\hline Young adults & $2.12(1.18,3.79)$ & 0.01 & & $1.54(0.81,2.93)$ & 0.2 & \\
\hline Adults & $3.14(1.76,5.63)$ & $<0.001$ & & $2.9(1.56,5.38)$ & $<0.001$ & \\
\hline Ethnicity of women: ref. = Indigenous Non-Indigenous & $1.77(1.11,2.83)$ & 0.02 & 0.02 & $1.71(1.04,2.8)$ & 0.03 & 0.03 \\
\hline Referral status: ref. $=$ Referred Not referred & & & & $3.77(1.27,11.15)$ & 0.02 & 0.006 \\
\hline
\end{tabular}

AOR Adjusted odds ratio, $\mathrm{Cl}$ Confidence interval, *Wald's test, ** Likelihood ratio test.

Factors included in the initial model for ANC decision-making were age at marriage of women, type of marriage arrangement, age and occupation of mother-in-law, and daughter-in-law and mother-in-law sharing same residence.

Factors included in the initial model for delivery decision-making were place of residence, occupation and age at marriage of women, place of ANC, gestational age at first ANC, willingness to attend ANC, education level of husband, per capita income, age and occupation of mother-in-law. 
Table 5 Agreement of the most influential person for ANC and delivery care by age groups

\begin{tabular}{|c|c|c|c|c|c|c|c|c|c|c|}
\hline \multirow[b]{3}{*}{ Teen's response } & \multicolumn{5}{|c|}{ Antenatal care } & \multicolumn{5}{|c|}{ Delivery care } \\
\hline & \multicolumn{5}{|c|}{ Husband's response } & \multicolumn{5}{|c|}{ Husband's response } \\
\hline & & Woman (\%) & Other (\%) & Total (\%) & & & Woman (\%) & Other (\%) & Total (\%) & \\
\hline & Woman & $9(8.6)$ & $20(19.0)$ & $29(27.6)$ & $K=0.02$ & Woman & $7(6.7)$ & $15(14.3)$ & $22(21)$ & $K=0.07$ \\
\hline & Other & $22(20.9)$ & $54(51.4)$ & $76(72.3)$ & $\mathrm{Kpa}=0.2$ & Other & $20(19.0)$ & $63(60)$ & $83(79)$ & $\mathrm{Kpa}=0.3$ \\
\hline & Total (\%) & $31(29.5)$ & $74(70.4)$ & $105(100)$ & & Total (\%) & $27(25.7)$ & $78(74.3)$ & $105(100)$ & \\
\hline \multicolumn{11}{|c|}{ Young adult's response } \\
\hline & Woman & 19 (18.8) & $30(28.6)$ & 49 (46.7) & $K=0.1$ & Woman & $9(8.6)$ & $23(21.9)$ & $32(30.5)$ & $K=0.08$ \\
\hline & Other & $14(13.3)$ & $42(40)$ & $57(54.3)$ & $\mathrm{Kpa}=0.2$ & Other & $15(14.3)$ & $58(55.2)$ & $73(69.5)$ & $\mathrm{Kpa}=0.3$ \\
\hline & Total (\%) & $33(31.4)$ & 72 (68.6) & $105(100)$ & & Total (\%) & $24(22.9)$ & $81(77.1)$ & $105(100)$ & \\
\hline \multicolumn{11}{|l|}{ Adult's response } \\
\hline & Woman & $34(32.4)$ & $25(23.8)$ & $59(56.2)$ & $K=0.1$ & Woman & $25(23.8)$ & $25(23.8)$ & $50(47.6)$ & $K=0.1$ \\
\hline & Other & $22(21)$ & $24(22.8)$ & $46(43.8)$ & $\mathrm{Kpa}=0.1$ & Other & $22(21)$ & $33(31.4)$ & $55(52.4)$ & $\mathrm{Kpa}=0.1$ \\
\hline & Total (\%) & $56(53.3)$ & $59(56.2)$ & $105(100)$ & & Total (\%) & 47 (44.8) & $58(55.2)$ & $105(100)$ & \\
\hline
\end{tabular}

K: kappa coefficient; Kpa: prevalence-adjusted kappa coefficient.

collection since this study aimed to identify the influential person of women who utilized the services. Thus, results cannot be generalized to pregnant women who do not utilize facility-based maternal health care services in Nepal. The respondents may have also felt the tendency of cultural norms on respecting their husbands and mothers-in-law, the so called autonomy effect, which may have overestimated the influence of other family members in decision-making, particularly among teens. However, all respondents were interviewed independently, thus the perception of social desirability was presumably less. Furthermore, the study subjects were forced to select the most influential person. This might have understated the role of other people who could have been jointly involved in the decision. The findings should be interpreted in the light of the context of Nepal where a safe delivery incentive program and national free delivery policy has been implemented which might have influenced the utilization of maternal health care services. Finally, we did not ask the subjects for the reason(s) why they ranked that person as the most influential on the woman's decision to utilize the maternal health care services.

\section{Conclusion}

Our study confirmed that both the woman and her husband had an influence on the decision to utilize maternal health care services based on the response from the woman herself, her husband and her mother-in law. It is evident that women in their teens and non-indigenous women are vulnerable groups and have a limited decisionmaking capacity on their utilization of maternal health services. The interventions for improving utilization of
ANC and delivery care should be emphasized on the couple, especially among teen pregnant women and their husband.

Both women and their husbands influenced the decision to utilize ANC and delivery care. However, husbands were more influential than their wives, especially husbands of teens and young adults. Agreement of the perception on the most influential person between the women and their husband was less useful. Husband involvement is thus crucial in developing strategies to improve utilization of maternal health care services. Further studies on the perception of influential persons should be expanded to communitybased settings.

\section{Abbreviations}

ANC: Antenatal care; AOR: Adjusted odds ratio; Cl: Confidence interval; MDG5: Millennium Development Goals 5; PMWH: Paropakar Maternity and Women's Hospital; TUTH: Tribhuvan University Teaching Hospital; WHO: World Health Organization.

\section{Competing interests}

The authors declare that they have no competing interests.

\section{Authors' contributions}

PU designed the study, conducted the data collection process, analyzed and interpreted the data, and prepared the manuscript. TL involved in all aspects of the study and manuscript preparation. ABS and NP helped to conceptualize the study, supported the data collection process and commented on the manuscript. All authors read and approved the final manuscript.

\section{Acknowledgements}

This study was a part of the thesis of the first author for fulfilling the requirements of a Master of Science degree in Epidemiology at Prince of Songkla University, Thailand. The research was funded by a grant from the Graduate School, Prince of Songkla University, Thailand. We would like to thank Mr. Edward McNeil for his valuable assistance in the statistical analysis and English editing of the manuscript. 


\section{Author details}

'Epidemiology Unit, Faculty of Medicine, Prince of Songkla University, Hat Yai, Songkhla, Thailand, 90110. 'Paropakar Maternity and Women's Hospital, Thapathali, Kathmandu, Nepal. ${ }^{3}$ Department of Obstetrics and Gynecology, Tribhuban University Teaching Hospital, Maharajgunj, Kathmandu, Nepal.

Received: 29 July 2014 Accepted: 18 December 2014

Published: 23 December 2014

\section{References}

1. WHO, UNICEF, UNFPA: Trends in maternal mortality 1990-2010. Geneva, Switzerland: WHO, UNICEF, UNFPA and The World Bank estimates; 2012. Available from: [http://www.searo.who.int/maldives/documents/ Trends_in_maternal_mortality_A4_1990-2010.pdf] [cited 2014 January 01]

2. WHO: Pregnant Adolescents, Delivering on global promises for hope. Geneva, Switzerland: World Health Organization; 2006. Available from: [http:// whqlibdoc.who.int/publications/2006/9241593784_eng.pdf?ua=1] [cited 2014 January 10]

3. WHO: Adolescent pregnancy - Unmet needs and undone deeds. A review of the literature and programmes. Geneva, Switzerland: Issues in Adolescent Health and Development; 2007. Available from: [http://whqlibdoc.who.int/ publications/2007/9789241595650 eng.pdf] [cited 2014 January 5]

4. WHO: Antenatal care in developing countries: promises, achievements and missed opportunities. An analysis of trends, levels and differentials, 1990-2001. Geneva, Switzerland: World Health Organization; 2003. Available from: [http://www.childinfo.org/files/antenatal_care.pdf] [cited 2014 January 5]

5. Robinson JJ, Wharrad $\mathrm{H}$ : The relationship between attendance at birth and maternal mortality rates: an exploration of United Nations' data sets including the ratios of physicians and nurses to population, GNP per capita and female literacy. J Adv Nurs 2001, 34:445-455.

6. Atuyambe L, Mirembe F, Tumwesigye NM, Annika J, Kirumira EK, Faxelid E: Adolescent and adult first time mothers' health seeking practices during pregnancy and early motherhood in Wakiso district, central Uganda. Reprod Health 2008, 5:13.

7. Rahman MM, Haque SE, Zahan MS: Factors affecting the utilisation of postpartum care among young mothers in Bangladesh. Health Soc Care Commun 2011, 19:138-147.

8. Adhikari R: Early marriage and childbearing: risks and consequences. Geneva, Switzerland: World Health Organization; 2003. Available from: [http:// whqlibdoc.who.int/publications/2006/9241593776_eng.pdf] [cited 2014 January 12]

9. Kingston D, Heaman M, Fell D, Chalmers B: Comparison of adolescent, young adult, and adult women's maternity experiences and practices. Pediatrics 2012, 129:e1228-e1237.

10. Edirne T, Can M, Kolusari A, Yildizhan R, Adali E, Akdag B: Trends, characteristics, and outcomes of adolescent pregnancy in eastern Turkey. Int J Gynaecol Obstet 2010, 110:105-108.

11. Ministry of Health and Population, New ERA, ICF International: Nepa Demographic and Health Survey 2011. Calverton, Maryland, USA: Ministry of Health and Population, New ERA, ICF International; 2012.

12. Gross K, Alba S, Glass TR, Schellenberg JA, Obrist B: Timing of antenatal care for adolescent and adult pregnant women in south-eastern Tanzania. BMC Pregnancy Childbirth 2012, 12:16.

13. Finlayson $\mathrm{K}$, Downe $\mathrm{S}$ : Why do women not use antenatal services in low- and middle-income countries? A meta-synthesis of qualitative studies. PLoS Med 2013, 10:e1001373.

14. United Nations: The Millennium Development Goals Report 2013. New York, USA: United Nations; 2013. Available from: [http://www.un.org/ millenniumgoals/pdf/report-2013/mdg-report-2013-english.pdf] [cited 2014 May 17]

15. Witter S, Khadka S, Nath H, Tiwari S: The national free delivery policy in Nepal: early evidence of its effects on health facilities. Health Policy Plan 2011, 26(Suppl 2):ii84-ii91.

16. Powell-Jackson T, Neupane BD, Tiwari S, Tumbahangphe K, Manandhar D, Costello AM: The impact of Nepal's national incentive programme to promote safe delivery in the district of Makwanpur. Adv Health Econ Health Serv Res 2009, 21:221-249.

17. Government of Nepal, United Nations Country Team of Nepal: Nepal Millennium Development Goals Progress Report 2013. Kathmandu, Nepal: Government of Nepal, United Nations Country Team of Nepal; 2013.
Available from: [http://planipolis.iiep.unesco.org/upload/Nepal/ Nepal_MDG_2013.pdf] [cited 2014 March 28]

18. Kaphle S, Hancock H, Newman LA: Childbirth traditions and cultural perceptions of safety in Nepal: critical spaces to ensure the survival of mothers and newborns in remote mountain villages. Midwifery 2013, 29(10):1173-1181.

19. Brunson J: Confronting maternal mortality, controlling birth in Nepal: the gendered politics of receiving biomedical care at birth. Soc Sci Med 2010, 71(10):1719-1727

20. Teferra AS, Alemu FM, Woldeyohannes SM: Institutional delivery service utilization and associated factors among mothers who gave birth in the last 12 months in Sekela District, North West of Ethiopia: a community-based cross sectional study. BMC Pregnancy Childbirth 2012, 12:74.

21. Doku D, Neupane S, Doku PN: Factors associated with reproductive health care utilization among Ghanaian women. BMC Int Health Hum Rights 2012, 12:29.

22. Mumbare SS, Rege R: Antenatal care services utilization, delivery practices and factors affecting them in tribal area of north maharashtra. Indian $J$ Community Med 2011, 36:287-290.

23. Simkhada B, Teijlingen ER, Porter M, Simkhada P: Factors affecting the utilization of antenatal care in developing countries: systematic review of the literature. J Adv Nurs 2008, 61:244-260.

24. Simkhada B, Porter MA, van Teijlingen ER: The role of mothers-in-law in antenatal care decision-making in Nepal: a qualitative study. BMC Pregnancy Childbirth 2010, 10:34.

25. Some DT, Sombie I, Meda N: How decision for seeking maternal care is made-a qualitative study in two rural medical districts of Burkina Faso. Reprod Health 2013, 10:8

26. Story WT, Burgard SA, Lori JR, Taleb F, Ali NA, Hoque DM: Husbands' involvement in delivery care utilization in rural Bangladesh: a qualitative study. BMC Pregnancy Childbirth 2012, 12:28

27. Liabsuetrakul T, Oumudee $\mathrm{N}$ : Effect of health insurance on delivery care utilization and perceived delays and barriers among southern Thai women. BMC Public Health 2011, 11:510

28. van Eijk AM, Bles HM, Odhiambo F, Ayisi JG, Blokland IE, Rosen DH, Adazu K, Slutsker L, Lindblade KA: Use of antenatal services and delivery care among women in rural western Kenya: a community based survey. Reprod Health 2006, 3:2.

29. Sabeena Jalal NAS: Ante Nata Care (ANC) seeking behavior among women living in an urban squatter settlement: results from an ethnographic study. Italian J Public Health 2011, 8(3):261-267.

30. Acharya DR, Bell JS, Simkhada P, van Teijlingen ER, Regmi PR: Women's autonomy in household decision-making: a demographic study in Nepal. Reprod Health 2010, 7:15.

31. Senarath U, Gunawardena NS: Women's autonomy in decision making for health care in South Asia. Asia Pac J Public Health 2009, 21(2):137-143.

32. Sim J, Wright CC: The kappa statistic in reliability studies: use, interpretation, and sample size requirements. Phys Ther 2005, 85:257-268.

33. Pembe AB, Urassa DP, Darj E, Carlsted A, Olsson P: Qualitative study on maternal referrals in rural Tanzania: decision making and acceptance of referral advice. Afr J Reprod Health 2008, 12:120-131.

34. White DDM, Rubardt M, Sissoko K, Stephenson R: The influence of intrafamilial power on maternal health care in Mali: perspectives of women, men and mothers-in-law. Int Perspect Sex Reprod Health 2013, 39:58-68.

35. UNDP in Thailand: Available from: [http://www.th.undp.org/content/ thailand/en/home/mdgoverview/overview/mdg3/] [cited 2014 March 12]

36. Thailand: health care for all, at a price. Available from: [http://www.who.int/ bulletin/volumes/88/2/10-010210/en/] [cited 2014 March 12]

37. Thapa DK, Niehof A: Women's autonomy and husbands' involvement in maternal health care in Nepal. Soc Sci Med 2013, 93:1-10.

38. Pregnancy and Childbirth in Nepal. Available from: [http://www.nsmp.org/ pregnancy childbirth nepal/] [cited 2014 March 4]

39. WHO: Adolescents, social support and help-seeking behavior. Geneva, Switzerland: World Health Organization; 2007. Available from: [http:// whqlibdoc.who.int/publications/2007/9789241595711_eng.pdf?ua=1] [cited2014 May 25]

40. Tuladhar S, Khanal KRKCL, Ghimire PK, Onta K: Women's Empowerment and Spousal Violence in Relation to Health Outcomes in Nepal: Further analysis of the 2011 Nepal Demographic and Health Survey. Calverton, Maryland, USA: 
Nepal Ministry of Health and Population, New ERA, and ICF International; 2013. Available from: URL: http://dhsprogram.com/pubs/pdf/FA77/FA77.pdf [cited 2014 May 28]

41. Arsenault C, Fournier P, Philibert A, Sissoko K, Coulibaly A, Tourigny C, Traore M, Dumont A: Emergency obstetric care in Mali: catastrophic spending and its impoverishing effects on households. Bull World Health Organ 2013, 91(3):207-216.

42. Kulczycki A: Husband-wife agreement, power relations and contraceptive use in Turkey. Int Fam Plan Perspect 2008, 34:127-137.

43. Mullany BC: Spousal agreement on maternal health practices in Kathmandu, Nepal. J Biosoc Sci 2010, 42:689-693.

doi:10.1186/1742-4755-11-92

Cite this article as: Upadhyay et al: Influence of family members on utilization of maternal health care services among teen and adult pregnant women in Kathmandu, Nepal: a cross sectional study. Reproductive Health 2014 11:92

\section{Submit your next manuscript to BioMed Central and take full advantage of:}

- Convenient online submission

- Thorough peer review

- No space constraints or color figure charges

- Immediate publication on acceptance

- Inclusion in PubMed, CAS, Scopus and Google Scholar

- Research which is freely available for redistribution 